\title{
PERANCANGAN APLIKASI SISTEM ADMINISTRASI PEMBAYARAN TOKO BONEKA RR BERBASIS JAVA NETBEANS
}

\author{
Garry Aditya Dharmawan \\ ${ }^{1,2,3}$ Teknik Informatika, Fakultas Teknik dan Ilmu Komputer, Universitas Indraprasta PGRI Jakarta \\ Jalan Raya Tengah No 80, Kelurahan Gedong, Pasar Rebo, Jakarta Timur \\ aditya.garry45@gmail.com
}

\begin{abstract}
ABSTRAK
Toko RR adalah sebuah toko yang bergerak disektor perdagangan khususnya dalam bidang penjualan boneka kain adapun masalah pada toko boneka RR ini yaitu, proses pembuatan rekapitulasi data transaksi oleh pegawai masih dilakukan secara manual dengan cara ditulis di buku besar. Tujuan dari penelitian adalah untuk membuat sebuah sistem sistem aplikasi administrasi pembayaran. Penulis melakukan pendekatan studi kasus dengan metode Deskriptif yaitu suatu bentuk penelitian yang bertujuan untuk memberikan gambaran sistematik dan akurat mengenai fakta, sifat dan hubungan antara fenomena yang. Hasil dari penelitian ini adalah umtuk membuat suatu perangkat aplikasi dengan bahasa pemrograman Java NetBeans dan dapat penyimpanan data menggunakan database dari MySQL sehingga proses pendataan pada Toko Boneka ini menjadi lebih efektif dan efisien.
\end{abstract}

Kata Kunci: Sistem Aplikasi Administrasi Pembayaran

\begin{abstract}
$R R$ store is a store that is engaged in the trade sector, especially in the field of selling cloth dolls, while the problem in this $R R$ doll shop is, the process of making recapitulation of transaction data by employees is still done manually by writing in the ledger. The purpose of this research is to create a payment administration application system. The author takes a case study approach with a descriptive method, which is a form of research that aims to provide a systematic and accurate description of the facts, nature and relationships between the phenomena studied. The result of this research is the existence of an application device made with the Java NetBeans programming language and data storage using a MYSQL database so that the data collection process at the RR Doll Shop becomes more effective and efficient.
\end{abstract}

Key Word: Aplication Payment Administration System

\section{PENDAHULUAN}

Pada zaman modern seperti sekarang ini, kebutuhan manusia banyak menggunakan jasa internet sebagai informasi dan menggapai suatu hal dengan mudah seiring pesat nya perkembangan teknologi di masyrakat. Seiring dengan perkembangan teknologi maka mempengaruhi perkembangan berwirausaha. Berkembangnya teknologi juga menjadikan informasi dan kegitan sehari hari yang dapat meningkatkan peluang berwirausaha menjadi lebih efesien. Teknologi yang berkembang di dukung oleh sarana dan prasarana dimana informasi telah menjadi kebutuhan pokok dalam kehidupan manusia dengan memberikan kelebihan - kelebihan yang tentu nya akan meningkatkan efesiensi dan efektifitas kerja di suatu usaha. Salah satunya adalah toko boneka yang memiliki jenis - jenis boneka yang menarik minat seseorang.
Toko RR adalah sebuah toko yang bergerak disektor perdagangan khususnya dalam bidang penjualan boneka kain, memiliki bermacammacam karakter dan model seperti boneka bear, monkey, kucing, stich, mickey mouse, angry bird dan lain-lain. Toko RR sudah ada cukup lama mulai berdiri tahun 2010 dan sampai sekarang masih berjalan. Toko boneka ini terletak di J1. Masjid RT.003/004 depan Puskesmas Cibubur Kec.Ciracas Jakarta Timur Untuk menghitung dan memperoses data - data pembelian dari distributor serta pengolahan persediaan boneka yang membutuhkan banyak waktu dan tenaga, proses tersebut meliputi percatatan seluruh kegiatan yang berada di dalam toko RR dan pembuatan laporan yang digunakan untuk melakukan kegiatan operasional bagi sebuah usaha perorangan digunakan untuk mengumpulkan, menyediakan 
dan mengolah informasi dengan tujuan untuk membantu menunjang efektifitas kerja. Toko boneka termasuk dalam bidang usaha perdagangan memerlukan adanya sebuah aplikasi pengolahan data untuk dapat mempermudah dan memperlancar kinerja kerja. Pada umum nya banyak toko boneka yang memberdayakan tenaga manusia sebagai mengolah suatu usaha.

Berdasarkan uraian masalah yang telah dijelaskan, maka toko boneka RR membutuhkan suatu sistem yang dapat menyelesaikan masalah saat ini. Salah satunya yaitu dengan membangun sistem yang diharapkan dapat membantu proses transaksi antara penjual dan pembeli, sehingga proses tersebut menjadi lebih efisien karena bisa di akses dimana saja dan kapan saja. Menurut Kadir (2014) sistem adalah sekumpulan elemen yang saling terkait atau terpadu yang dimaksudkan untuk mencapai suatu tujuan. Sedangkan perancangan adalah proses pengembangan spesifikasi baru berdasarkan rekomendasi hasil analisis sistem (Subhan,2012:109). Sehingga Azhar Susanto menjelaskan dalam buku berjudul Sistem Informasi Manajemen Konsep Perkembangannya (2013) yaitu: "perancangan sistem adalah spesifikasi umum dan terinci dari pemecahan masalah berbasis komputer yang telah dipilih selama tahap analisis”.

Perancangan sistem ini perlu dilakukan untuk membantu toko boneka RR dalam mempermudah sistem pembayarannya. Terdapat beberapa penelitian yang telah dalam merancang aplikasi dengan berbagai platform. Beberapa diantaranya dilakukan oleh (Dwiprastio et al., 2012) dengan judul Aplikasi Penjualan dan Persediaan Barang Dagang dengan Metode Perpetual FIFO Berbasis Web (Studi Kasus pada PD. XYZ). Penelitian ini menghasilkan sebuah aplikasi yang berfungsi untuk mengelola kas atas transaksi keluar masuk barang dari perusahaan. Penelitian lainnya dilakukan oleh (Cakra Udaksana, Adityar Praja, 2018), (Rizal et al., 2021), dan (Bushairi et al., 2021) yang merancang aplikasi berbasis Java Neatbens. Kesimpulan dari kedua penelitan tersebut bahwa dengan adanya aplikasi yang dibuat, bagian pengelolaan administrasi dapat menangani penginputan update data tentang administrasi dengan cepat dan mudah dalam berbagai kasus studi. Selain web dan Java, ada juga yang berbasis android seperti yang dilakukan oleh (Wirayudha et al., 2017) dan (Zaliluddin, 2021).

Pada penelitian ini, penulis juga merancang aplikasi pada sistem admisitrasi pembayaran pada toko RR berbasis Java Netbeans. Menurut A.S., Rosa dan Shalahuddin, M. dalam bukunya yang berjudul Rekayasa Perangkat Lunak (2015:103) mengatakan bahwa "Java menurut definisi dari Sun Microsystem adalah nama untuk sekumpulan teknologi untuk membuat dan menjalankan perangkat lunak pada komputer standalone ataupun pada lingkungan jaringan. Sedangkan Netbeans mempunyai lingkupan pemrograman yang terintegrasi dalam suatu perangkat lunak yang didalamnya menyediakan pembangunan pemrograman GUI, text editor, compiler, dan interpreter (Westriningsih, 2012).

Tujuan penelitian untuk menunjang sistem manual dengan menggunanakan teknologi computer, Untuk merancang aplikasi penjualan yang dapat membantu proses pengolahan data pada toko boneka RR, Untuk membantu dalam proses perhitungan biaya sehingga lebih cepat, efektif dan efesien. Manfaat penelitian bagi penulis, toko boneka RR dapat mengembangkan sistem yang sedang berjalan menjadi lebih efektif sehingga dapat menunnjang kemajuan usaha, Menerapkan ilmu yang didapat selama perkuliahan, Mempermudah dalam mendapatkan laporan penelitian terkait manajemen pembayaran. Bagi Perusahaan dapat memberikan suatu karya penelitian yang dapat mendukung dalam pengembangan aplikasi penjualan, Membantu menemukan prototype sederhana dalam membangun sistem aplikasi penjualan, Menambah wawasan ilmu dibidang akademik penerapan ilmu yang telah dipelajari serta diharapkan untuk meningkatkan kinerja wawasan penulis untuk kedepannya. Oleh karena itu, dengan mempertimbangkan permasalahan, tujuan dan manfaat yang akan diperoleh berbagai pihak, penulis mengambil judul penelitian Perancangan Aplikasi Sistem Administrasi Pembayaran Toko Boneka RR Berbasis Java Netbeans.

\section{METODE PENELITIAN}

Dalam penyusunan penulis melakukan pengumpulan data sebagai dasar pemikiran dalam menyusun sistem, yaitu dengan metodemetode sebagai berikut : 
Data dan informasi yang diperoleh untuk menguatkan penelitian ini diambil dari data yang diperoleh melalui tanya jawab langsung ke Pengusaha Toko Boneka RR.

Studi Pustaka (Library Research)

Pengumpulan data dan informasi diambil dari kutipan-kutipan buku di perpustakaan Universitas Indraprasta PGRI. Dari bahan-bahan tersebut diambil teori-teori yang dapat dijadikan landasan untuk menganalisa masalah yang dikemukakan dalam penelitian.

\section{Studi Lapangan (Field Research)}

Studi lapangan ini penulis lakukan untuk mengamati secara langsung terhadap penerapan sistem informasi penyewaan alat/barang. Dalam studi lapangan ini digunakan teknik pengumpulan data antara lain dengan cara:

Observasi adalah cara untuk mengamati secara langsung proses yang digunakan oleh bagian penjualan atau kasir dalam kegiatan pengolahan data pemasukan toko.

Wawancara adalah teknik pengumpulan data dengan cara bertanya langsung kepada pelaksana yang terlibat langsung. Wawancara tidak hanya sebatas wawancara pengguna, tetapi juga para pengambil keputusan dan kebijakan.

1. Sumber Data

informasi yang diperoleh untuk mengguatkan penelitian ini diambil dari dua sumber yaitu sumber data primer yang diperoleh langsung dari responden melalui survei dan sumber data sekunder yang merupakan data pendukung untuk melengkapi data primer yang diperoleh melalui tanya jawab langsung atau dokumen. Bahasa program yang di gunakan adalah Java, Menurut Rosa dan M. Shalahuddin dalam bukunya yang berjudul Rekayasa Perangkat Lunak (2015:103) mengatakan bahwa "Java menurut definisi dari Sun Microsystem adalah nama untuk sekumpulan teknologi untuk membuat dan menjalankan perangkat lunak pada komputer standalone ataupun pada lingkungan jaringan

\section{HASIL DAN PEMBAHASAN}

\section{Analisa Permasalahan}

Dari hasil analisa yang dilakukan dapat ditarik kesimpu:lan permasalahan yang ada pada Toko Boneka RR.
1. Sistem yang diterapkan atau yang sedang berjalan mengenai penjualan boneka masih menggunakan pencatatan manual ditinjau dari segi fungsi penjualan boneka agar lebih mudah mendapatakan informasi mengenai ketersediaan boneka, maka dibutuhkan nya sistem informasi yang terintegrasi.

2. Pengolahan data dengan menggunakan pencatatan manual ini dapat terjadi kekurangan dan kesalahan dalam penulisan yang berdampak pada pelaporan data ke Toko.

3. Dengan menggunakan metode diatas, kasir sering mengalami masalalah khusus nya dalam ketersediaan barang.

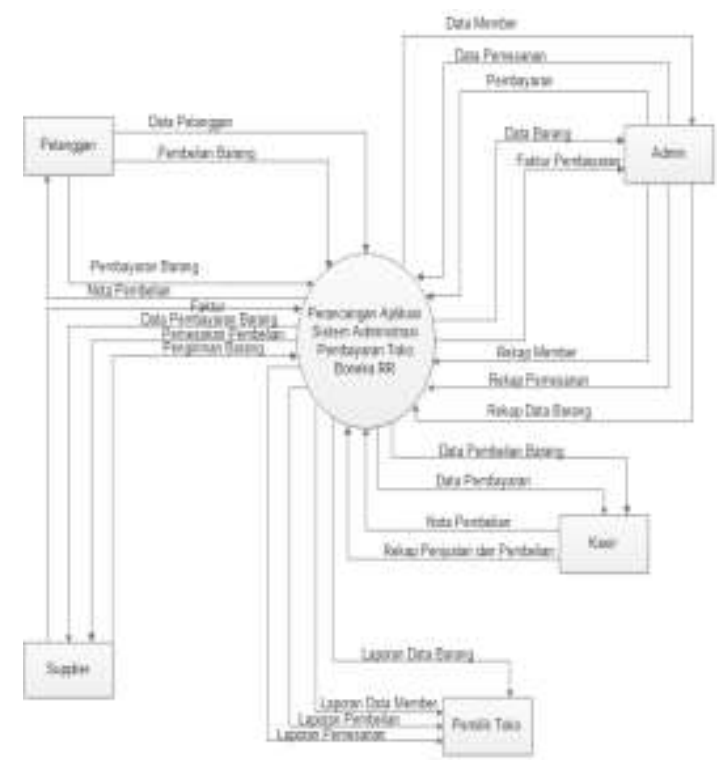

Gambar 1. Diagram Konteks

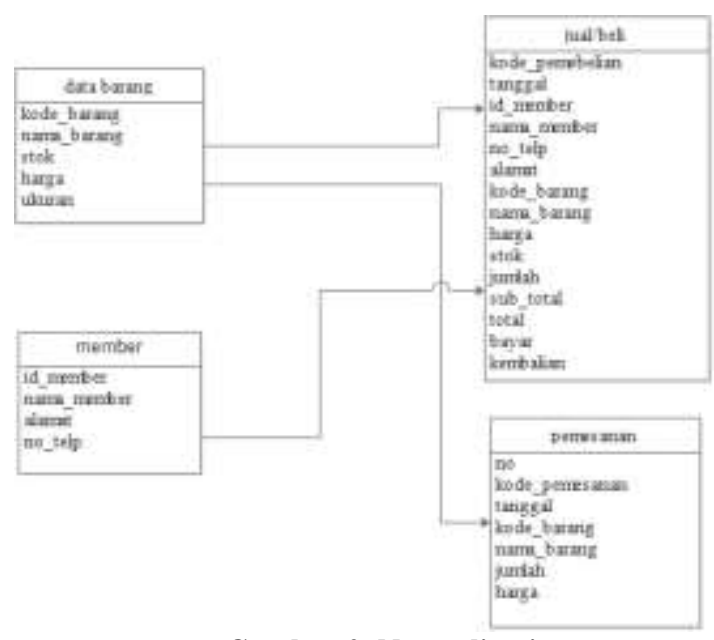

Gambar 2. Normalisasi 


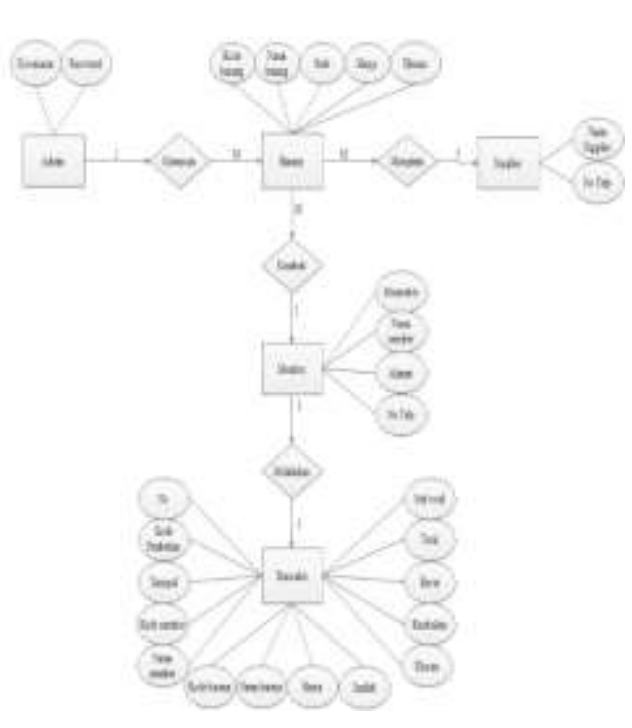

Gambar 3. ERD (Entity Relationship Diagram)

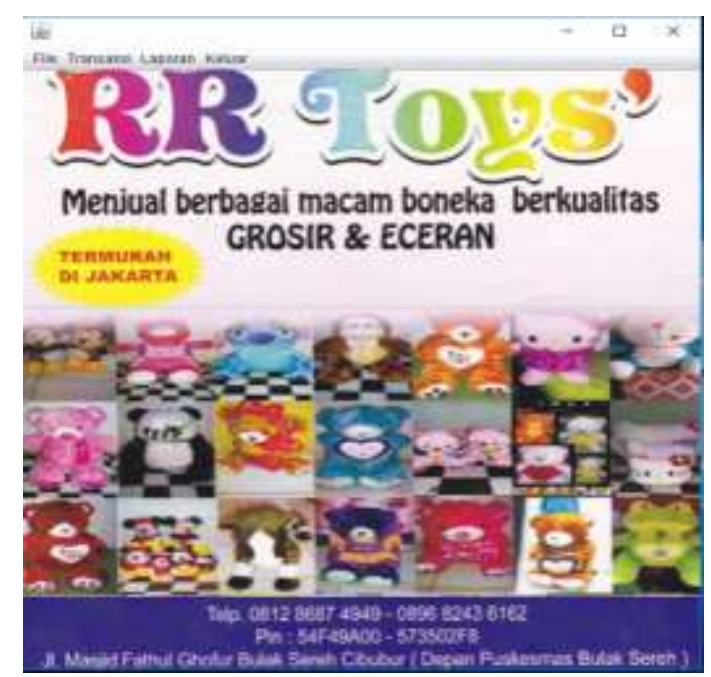

Gambar 4. Form Menu Utama

1) Menu Login, untuk dapat mengakses semua menu yang ada harus masuk sebagai admin.

2) Menu member, untuk memasukan data customer baru yang melakukan transaksi jual beli pada toko boneka rr.

3) Menu Data Barang, untuk memasukan data barang yang dijual pada toko boneka rr.

4) Menu Transaksi_Pembelian, untuk menginput data transaksi pembelian yang dilakukan oleh customer.

5) Menu Pemesanan, untuk menginput data pemesanan barang.

6) Menu Laporan Data Barang, untuk membuat dan mencetak laporan data barang yang ada.

7) Menu Laporan, untuk membuat dan mencetak laporan member, databarang, pembelian dan pemesanan yang terjadi pada toko boneka RR.

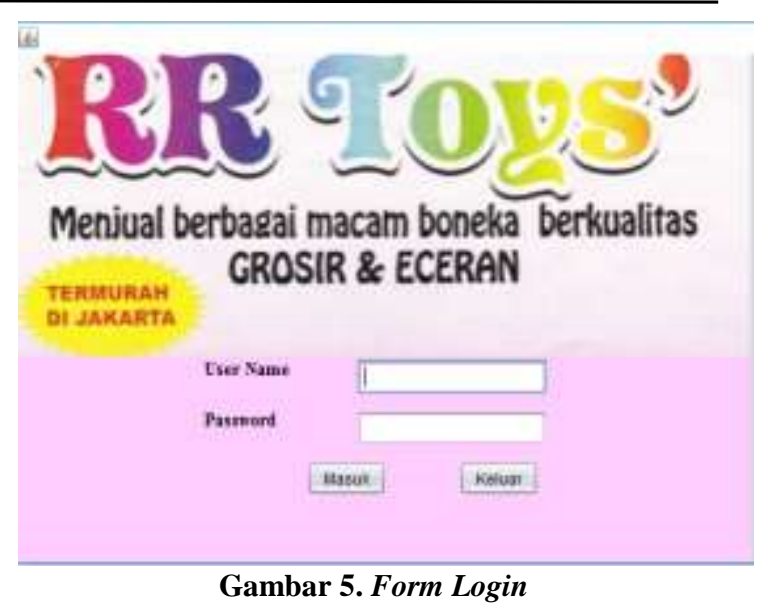

Gambar diatas menampilkan menu login perancangan sistem aplikasi administrasi pembayaran pada toko boneka rr, terdapat dua tombol masuk dan keluar. Tombol masuk untuk melanjutkan kedalam menu utama yang memerlukan username dan password agar dapat mengaksesnya semua data yang ada didalam menu utama, sedangkan tombol keluar untuk mengakhiri dan keluar dari aplikasi.

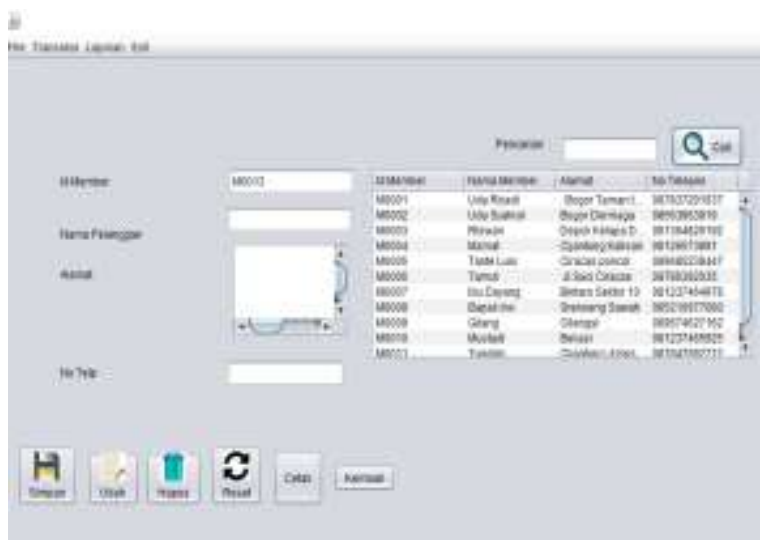

\section{Gambar 6. Form Data Member}

Halaman form input data member digunakan oleh admin untuk menambah data customer yang melakukan jual beli. Terdapat tombol aksi yaitu simpan, hapus, ubah, reset, cetak dan cari. Serta terdapat menu bar yang dapat digunakan sesuai fungsinya.

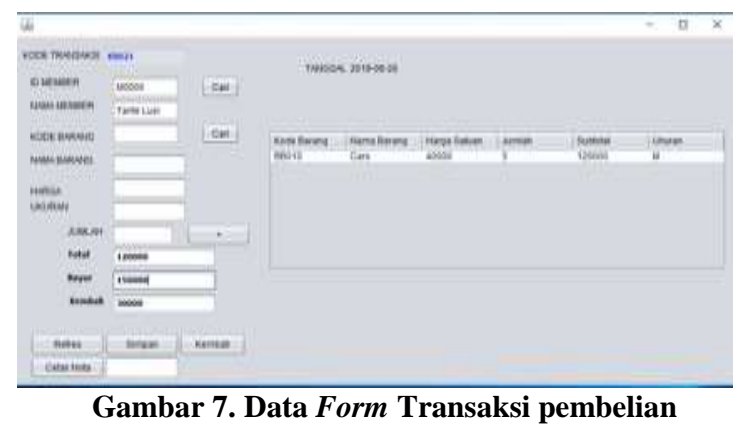


Halaman form input transaksi pembelian barang digunakan oleh admin untuk menambah data penjualan barang yang terjadi pada toko boneka rr. Terdapat tombol aksi yaitu tambah, simpan, refresh, cetak nota dan cari yang dapat digunakan sesuai dengan keinginan karyawan atau user serta terdapat menubar yang dapat digunakan sesuai fungsinya

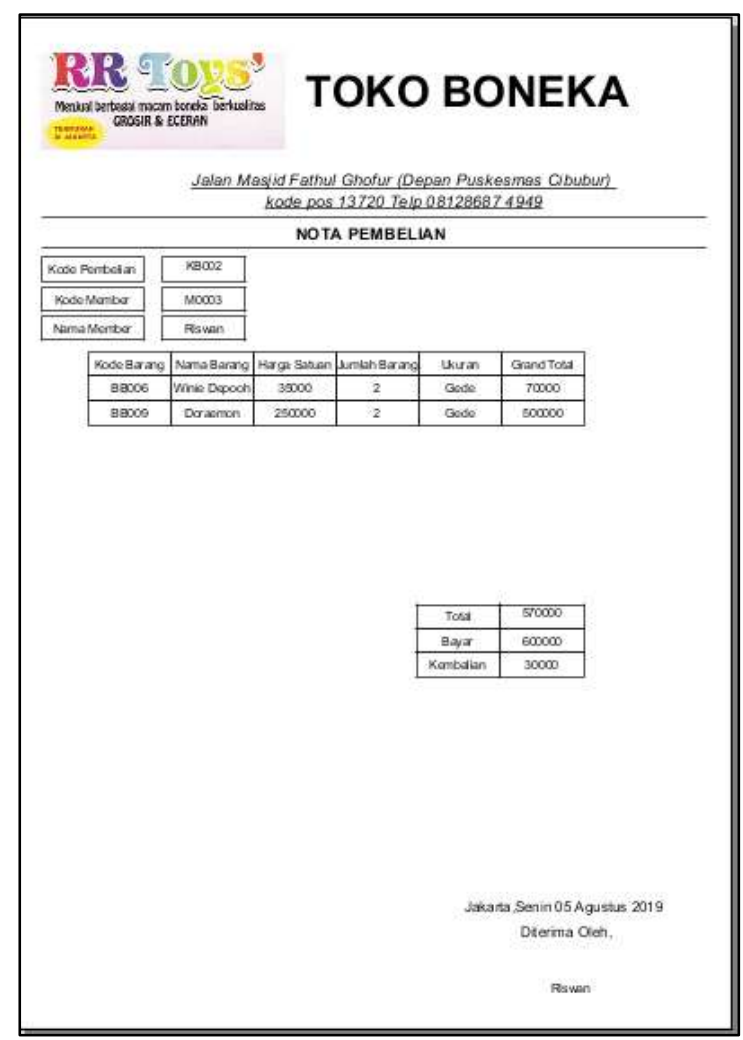

Gambar 8. Form Nota Pembelian

Tampilan report untuk menampilkan hasil transaksi yang nantinya di berikan kepada pembeli.

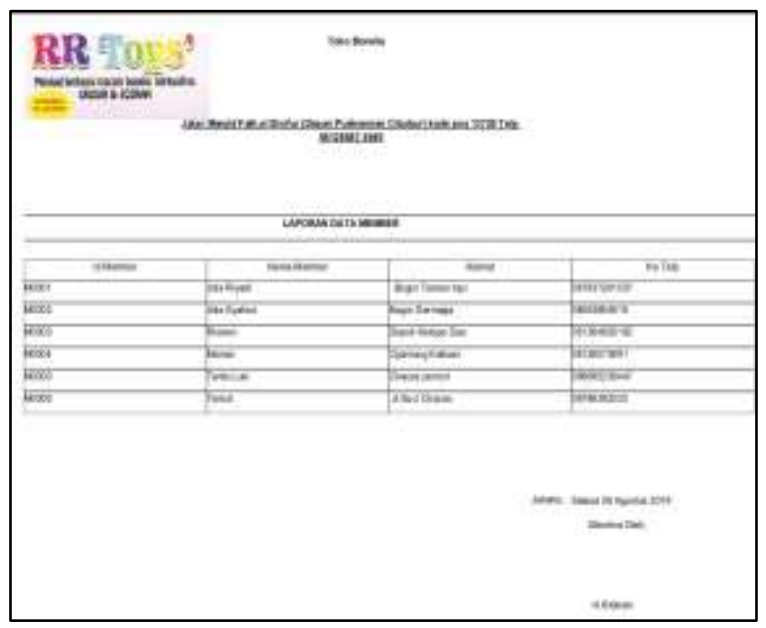

Gambar 9. Laporan Pembelian Keseluruhan
Tampilan report seluruh transaksi pembelian

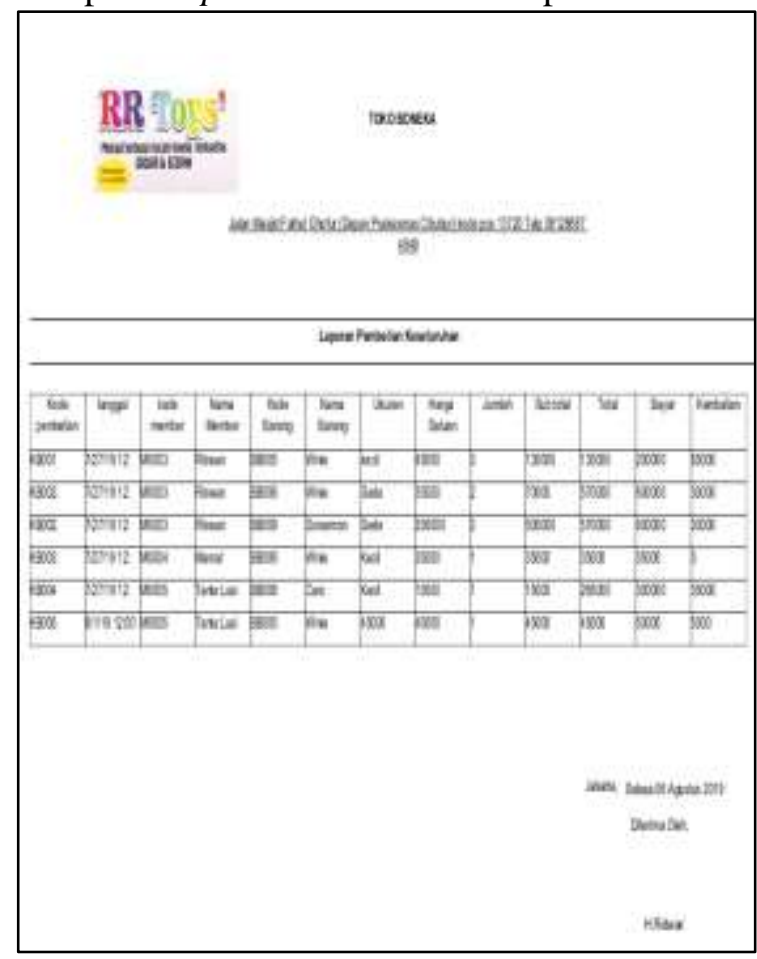

Gambar 10. Laporan Pemesanan

Tampilan report seluruh data pemesanan boneka.

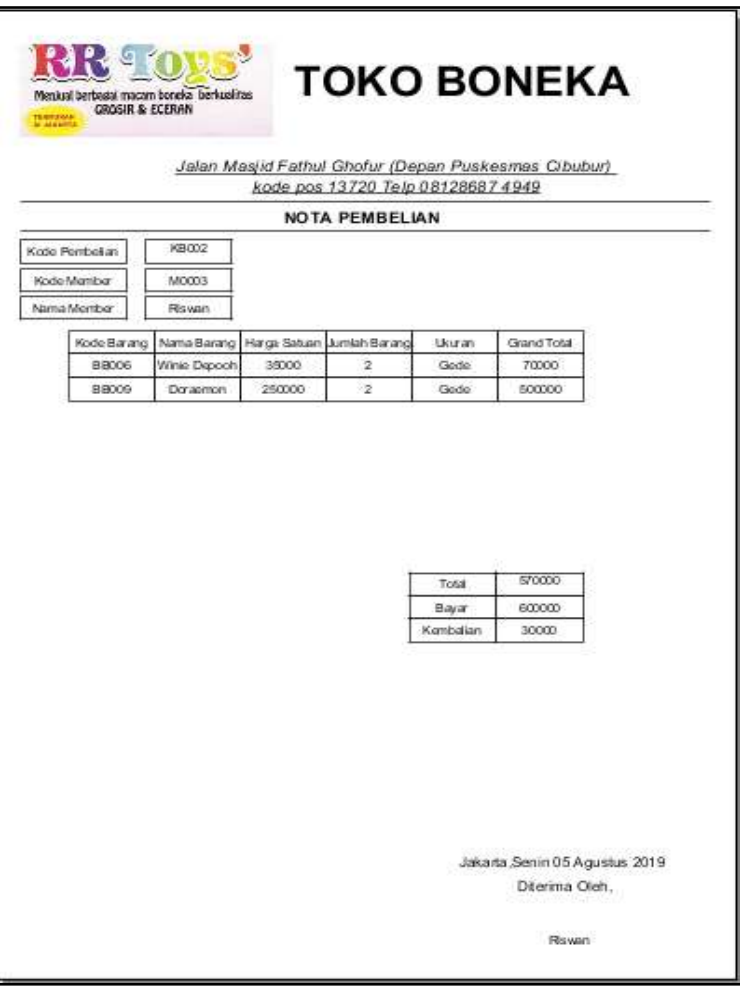

Gambar 11. Nota Pembelian 
Tampilan report seluruh pembelian barang.

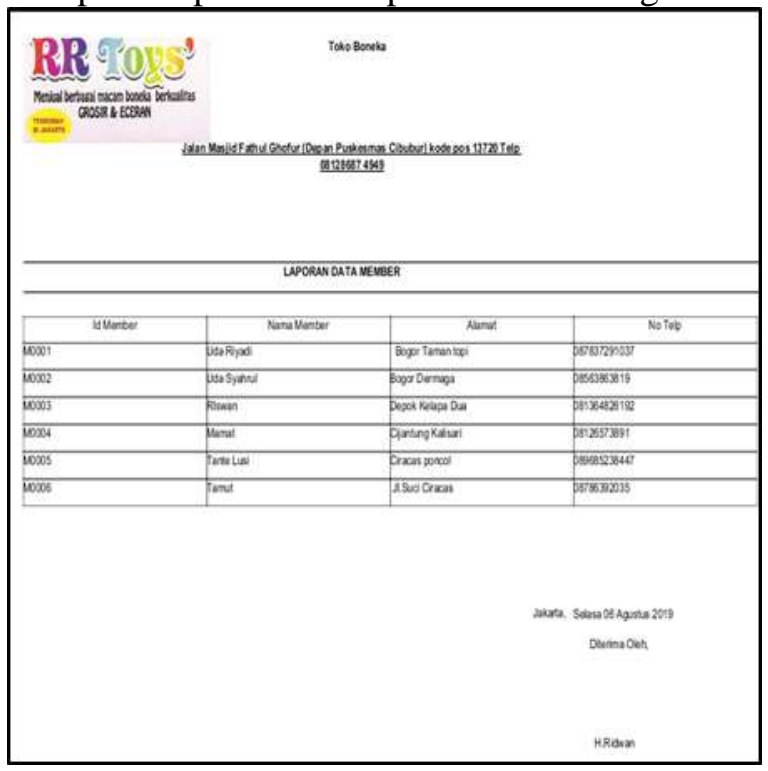

Gambar 12. Laporan Data Member

Tampilan report seluruh data member toko boneka RR

\section{SIMPULAN DAN SARAN}

Dengan dibuatnya aplikasi Administrasi pembayaran semua kegiatan yang berhubungan dengan Penjualan, dan data data barang yang terkait Pada Toko Boneka RR bisa beroprasi lebih baik lagi. Pada aplikasi ini, bagian administrasi dapat menangani pekerjaan penginputan data-data pengelolaan data penjualan dan laporan data pembelian serta stok barang yang masuk dan keluar dengan mudah. dengan adanya aplikasi ini diharapkan akan mempermudah seluruh kegiatan. Dengan diterapkannya Sistem Administrasi merupakan salah satu langkah maju dalam penerapan teknologi informasi.

Sejalan dengan sistem usulan yang penulis buat, maka demi tercapainya tujuan dan sasaran yang diharapkan, maka penulis dapat memberi saran sebagai berikut :

1. Rancangan aplikasi Sistem Adminsitrasi Pembayaran dapat dikembangkan kembali dalam hal disagin atau penambahan database sesuai kebutuhan pengolahan data.

2. Rancangan aplikasi Sistem Administasi Pembayaran haruslah didukung oleh sistem yang disiplin dan peraturan yang baik sesuai ketetapan bersama agar dapat berjalan dengan semestinnya.
Adanya Aplikasi Administrasi Pembayaran ini diharapkan mampu memberikan manfaat bagi Instansi. Untuk mendapatkan manfaat yang maksimal, maka penulis mengajukan beberapa saran:

1. Pengecekan data barang yang tersimpan pada database di dalam komputer sebaiknya dilakukan secara berkala, misalnya satu minggu atau satu bulan sekali.

2. Mengembangkan sistem yang telah diusulkan dengan menggunakan sistem yang lebih baik lagi

3. Sistem ini diharapkan dapat dimanfaatkan sebagaimana mestinya tanpa adanya penyalahgunaan pada informasi yang diberikan.

\section{DAFTAR PUSTAKA}

A.S., Rosa dan Shalahuddin, M. (2015). Rekayasa Perangkat Lunak Terstruktur dan Berorientasi Objek.Bandung: Informatika Bandung.

Bushairi, A., Pravitasari, N., Raya, J., No, T., Gedong, K., Rebo, P., \& Timur, J. (2021). Sistem Informasi Administrasi Layanan Intenet Berbasis Java (Studi Kasus: Pt Centra Sarana Data Jakarta Pusat ). Seminar Nasional Riset dan Inovasi Teknologi (SEMNAS RISTEK) 2021. 951955.

Cakra Udaksana, Adityar Praja, W. R. K. (2018). Rancang Bangun Aplikasi Digital School. 9th Industrial Research Workshop and National Seminar, 332-336.

Dwiprastio, C., Karismariyanti, M., \& Sukawati, R. (2017). Aplikasi Penjualan dan Persediaan Barang Dagang dengan Metode Perpetual FIFO Berbasis Web (Studi Kasus pada PD. XYZ). Jurnal Teknologi Informasi, 1(3), 82-87. Retrieved from //journals.telkomuniversity.ac.id/jti/a rticle/view/442

Kadir A. (2003). Konsep \& Tuntunan Praktis Basis Data. Yogyakarta: Andi Offset.

Rizal, W. M., Bustanul, N., \& Hutajulu, B. M. W. (2021). Perancangan Aplikasi Administrasi Siswa Pada Smk Al Muhajirin Di Depok Berbasis Java Netbeans. Just IT: Jurnal Sistem Informasi, Teknologi Informasi Dan Komputer, 11(2), 25-31. 
Subhan, M. (2012). Analisa Perancangan Sistem. Jakarta : Lentera Ilmu Cendikia.

Susanto, Azhar. 2013. Sistem Informasi Manajemen. Bandung: Lingga Jaya

Westriningsih. 2012. Panduan Aplikatif \& Solusi (PAS) Membangun Aplikasi Bisnis dengan Netbeans 7. Andi. Yogyakarta.

Wirayudha, S., Pribadi, T. W., \& Arif, S. (2017). Perancangan Aplikasi Berbasis Android untuk Aktivitas Manajemen Material Galangan Kapal Baru. Jurnal Teknik ITS $6(2)$

Zaliluddin, D. (2021). Aplikasi Administrasi Online Berbasis Android Menggunakan Pelayanan Masyarakat Ditengah Pandemi Covid19. Jurnal Sistem Informasi. 8(2), 96-99. 